\title{
Intrathoracal cholecystitis calculosa in a right-sided posttraumatic diaphragmatic hernia: a case report
}

\author{
Laura L Tahiri ${ }^{1}$, Afrim Tahiri ${ }^{*}$, Rifat Bajrami ${ }^{1}$, Shpresa Hasimja ${ }^{2}$ and Antigona Hasani ${ }^{2}$
}

\begin{abstract}
Introduction: Injuries of the diaphragm were first described in 1541 by Sennertus and the initial repair was performed by Riolfi in 1886. Posttraumatic diaphragmatic hernia in adults is usually caused by blunt trauma and may remain asymptomatic and undiagnosed for many years. Right-sided tears are significantly less likely than leftsided tears because of the protective effect of the liver. They are associated with high mortality and morbidity. The rupture of the right side of the diaphragm and the presence of an inflamed gallbladder in the thoracic cavity are uncommon.
\end{abstract}

Case presentation: We present the case of a 57-year-old Albanian man with prolapses of his gallbladder and other abdominal organs into the thoracic cavity through the herniation of his right hemidiaphragm due to trauma. The diaphragmatic hernia and gallstones seen in the thorax computed tomography scan were diagnostic. The organs herniated to the thoracic cavity were placed back into the abdominal cavity, a cholecystectomy was performed and the defect in the diaphragm was repaired with a prolene mesh graft during the operation. The patient was discharged 10 days after the surgical procedure, and no complications were reported.

Conclusion: Diaphragmatic hernia should be considered as a possible diagnosis in patients with respiratory disorders or unusual shadows in the thoracic region after recently sustained injury or with a history of injury. The prolapse of a gallbladder is rare. The symptoms are uncharacteristic and patients with this disease may remain without symptoms for a long period. Treatment is surgical.

\section{Introduction}

Injuries of the diaphragm were first described in 1541 by Sennertus and the initial repair was performed by Riolfi in 1886 [1]. Posttraumatic diaphragmatic hernia in adults is usually caused by blunt trauma and may remain asymptomatic and undiagnosed for many years. We report a case of delayed presentation of a patient with a rupture on the right side of his diaphragm and herniation of his abdominal organs and gallbladder (with stones) into the thorax. The rupture of the right side of the diaphragm and the presence of an inflamed gallbladder in the thoracic cavity are uncommon.

\footnotetext{
* Correspondence: dr.afrimi@hotmail.com

'University Clinical Center of Kosova, Clinic of Surgery, Rrethi i Spitalit pn, 10000, Prishtina, Republic of Kosova

Full list of author information is available at the end of the article
}

\section{Case presentation}

A 57-year-old Albanian man admitted to the emergency department presented with a 10-day history of rightsided epigastric and chest pain, together with a mild cough, distension of the abdomen, and constipation. The pain had been treated with analgesics. The patient had had a traffic accident seven years previously. After the accident, in the emergency room, he had undergone drainage to the right side of the thorax because of pleural effusion and the splinting of his upper arm due to a humerus fracture on the same side. An abdominal ultrasound examination, at that time, had confirmed no evidence of organ injury.

On arrival at the emergency department, the presence of gallstones was suspected, but none of the preclinical results supported this diagnosis. He was afebrile; his abdomen was inflated and insensitive to palpation. All laboratory results were within normal limits except for

\section{Biomed Central}




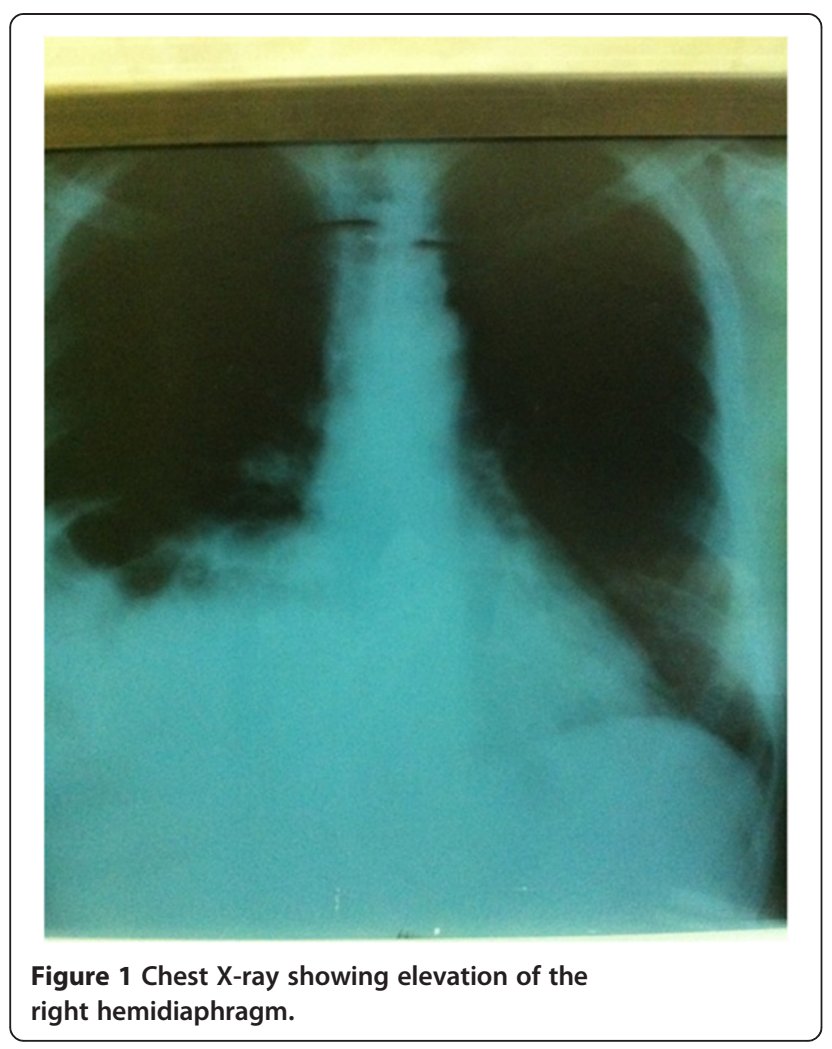

right hemidiaphragm. leucocytosis. The initial chest X-ray showed elevation of the right hemidiaphragm, an infiltrative shadow in the basal lobe of his right lung, and multiple radiolucencies over his right hemithorax (Figure 1). The stones in the gallbladder were invisible. Black pigment or mixed gallstones may contain sufficient calcium to appear radiopaque on plain films. Only 15 to 20 percent of gallstones are visible on simple radiographs [2].

The definite diagnosis was made through a thoracicabdominal computed tomography (CT) scan, which revealed intrathoracic displacement of his liver and part of the colon, and his gallbladder with regular walls and with three $17 \mathrm{~mm}$ stones around its neck (Figures 2 and 3 ).

The patient underwent surgical intervention via an abdominal approach. Intraoperative findings confirmed that the omentum, colon, gallbladder and 70 percent of his liver had herniated into the thoracic cavity. The organs were placed back into the abdominal cavity. The omentum was dissected off its adhesions and retrieved. A cholecystectomy was performed, and three stones were found in the gallbladder. The defect in the diaphragm, measuring $13 \mathrm{~cm} x 8 \mathrm{~cm}$, was repaired with a prolene mesh graft. A right-sided chest tube was inserted for drainage. The patient remained stable during the intraoperative phase. Postoperative recovery was uneventful, and he was well at the follow-up. The chest drain was removed on the fifth day after the surgery. The patient was discharged 10 days after the surgical procedure without any problems.

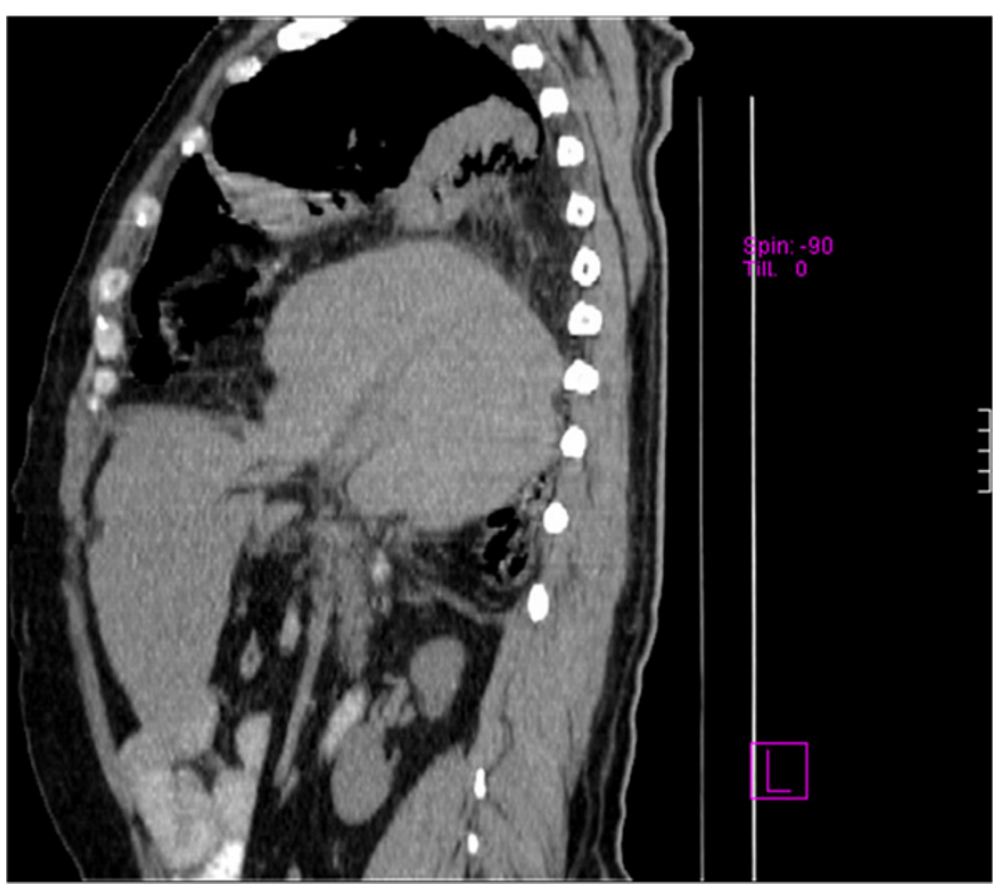

Figure 2 Computed tomography (CT) scan showing intrathoracal displacement of two-thirds of the liver. 


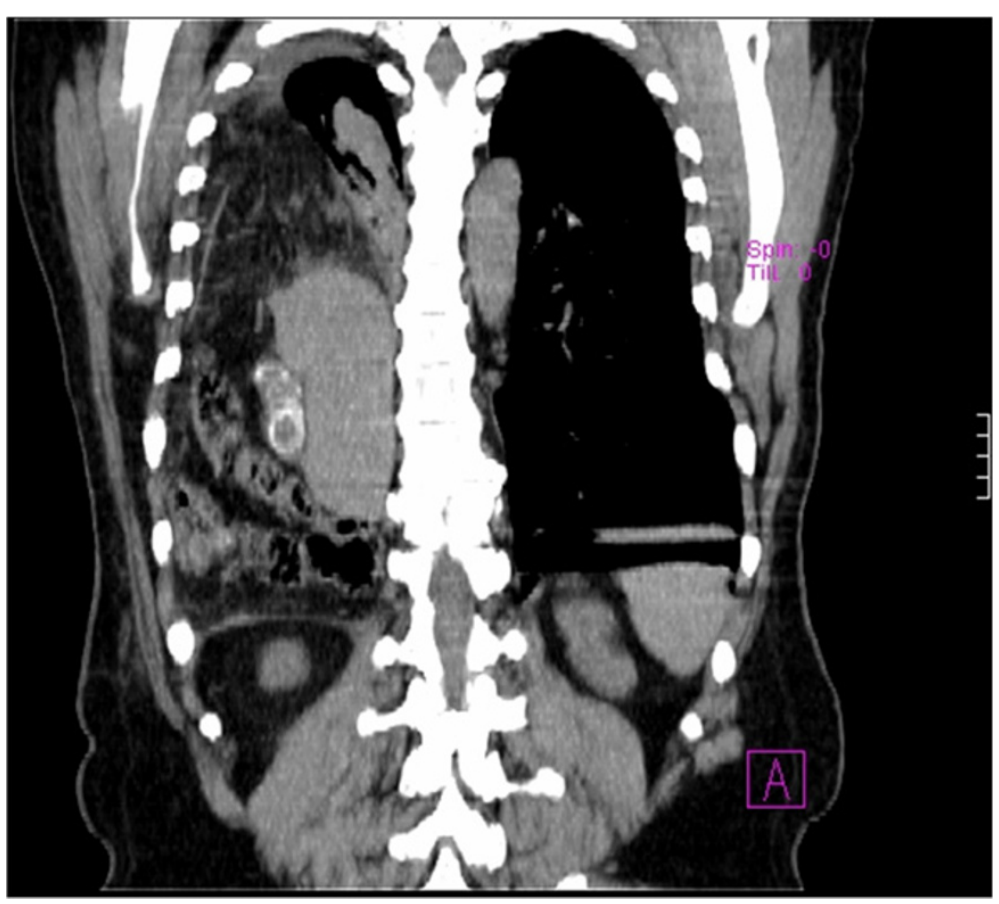

Figure 3 Computed tomography (CT) scan showing intrathoracal displacement of the cholecyst with three stones.

\section{Discussion}

Rupture of the diaphragm is a serious complication of blunt trauma. Diaphragmatic hernia is often initially overlooked in the acute setting and is only correctly diagnosed in 30 to 40 percent of cases [3-5]. In our case, diaphragmatic injury was diagnosed seven years after the injury.

A rupture of the right side of the diaphragm is uncommon. Approximately 69 percent of hernias are left-sided, 24 percent are right-sided, and 15 percent are bilateral [6]. Although autopsy studies have revealed equal incidence of right- and left-sided diaphragmatic ruptures, antemortem study reports suggest 88 to 95 percent of them occur to the left side [7-9]. Right-sided tears are significantly less likely than left-sided tears because of the protective effect of the liver. They are associated with high mortality and morbidity $[10,11]$.

Prolapse of the gallbladder is rare. There are just a few articles that report the presence of the gallbladder in posttraumatic diaphragmatic hernia [12-17]. In our case, an impeded presentation of the ruptured diaphragm and the presence of the gallbladder can be explained by the hypothesis of delayed detection. The 'delayed detection' hypothesis assumes that a diaphragmatic defect created at the time of the injury becomes clinically evident only when herniation occurs or when problems arise from the hernia contents. In our case, the symptoms appeared with the presence of stones in the gallbladder $[1,18]$.

The operative treatment for diaphragmatic rupture consists of hernia reduction, pleural drainage and repair of the defect [19]. The surgical approach could be either transabdominal or transthoracic, or both. However, laparoscopic surgery, thoracoscopy, or artificial patches have become very popular in recent years. Our patient underwent a transabdominal approach and a mesh repair of his diaphragmatic hernia. A transabdominal approach is recommended for a cholecystectomy, even if the gallbladder is in the thoracic cavity. On the other hand, the mesh decreased the risk of a recurrence of the hernias. This was caused by the shearing of a stretched membrane and avulsion of the diaphragm from its points of attachments due to a sudden increase in intraabdominal pressure, transmitted through the viscera.

\section{Conclusions}

Diaphragmatic hernia should be considered as a possible diagnosis in patients with respiratory disorders or unusual shadows in the thoracic region after recently sustained injury or with a history of injury. The prolapse of a gallbladder is rare. The symptoms are uncharacteristic and patients with this disease may remain without symptoms for a long period. Treatment is surgical.

\section{Consent}

Written informed consent was obtained from the patient for publication of this case report and accompanying images. A copy of the written consent is available for review by the Editor-in-Chief of this journal. 


\section{Competing interests}

The authors declare that they have no competing interests.

\section{Authors' contributions}

AT and RB analyzed and interpreted the patient data regarding the diagnosis and performed the surgery. LT and $\mathrm{AH}$ were major contributors in writing the manuscript, SH performed the anesthesia and postoperative treatment. All authors read and approved the final manuscript.

\section{Author details}

'University Clinical Center of Kosova, Clinic of Surgery, Rrethi i Spitalit pn, 10000, Prishtina, Republic of Kosova. ${ }^{2}$ University Clinical Center of Kosova, Clinic of Anesthesiology, Rrethi i Spitalit pn, 10000, Prishtina, Republic of Kosova.

Received: 7 November 2012 Accepted: 21 February 2013

Published: 2 April 2013

\section{References}

1. Goh BK, Wong AS, Tay KH, Hoe MN: Delayed presentation of a patient with a ruptured diaphragm complicated by gastric incarceration and perforation after apparently minor blunt trauma. CJEM 2004, 6:277-280.

2. Harris HW: Biliary system. In Surgery: Basic Science and Clinical Evidence. 2nd edition. Edited by Norton JA, Barie PS. New York: Springer Science+Business Media; 2008:911-942.

3. Faul JL: Diaphragmatic rupture presenting forty years after injury. Injury 1998, 29:479-480.

4. Meyers BF, McCabe CJ: Traumatic diaphragmatic hernia. Ann Surg 1993, 218:783-790.

5. Hejmdal A, Dakhil A, Boel T: Diaphragmatic hernia-admitted under the gallstone diagnosis. Ugeskr Laeger 2009, 171:33-34.

6. Maish MS: The diaphragm. Surg Clin North Am 2010, 90:955-968.

7. Disler DG, Deluca SA: Traumatic rupture of the diaphragm and herniation of the liver. Am Fam Physician 1992, 46:453-456.

8. Launey Y, Geeraerts T, Martin L, Duranteau J: Delayed traumatic right diaphragmatic rupture. Anesth Analg 2007, 104:224-225.

9. Ruiz-Tovar J, Gracia PC, Castineiras VM, Martinez EM: Post trauma diaphragmatic hernia. Rev Gastroenterol Peru 2008, 28:244-247.

10. Peker $Y$, Tatar F, Kahya MC, Cin N, Derici H, Reyhan E: Dislocation of three segments of the liver due to hernia of the right diaphragm: report of a case and review of the literature. Hernia 2007, 11:63-65.

11. Wirbel RJ, Mutschler W: Blunt rupture of the right hemi-diaphragm with complete dislocation of the right hepatic lobe: report of a case. Surg Today 1998, 28:850-852.

12. Neef $H$ : Transthoracic cholecystectomy and choledochus revision in chronic rupture of the right diaphragm. Zentralb/ Chir 1994, 119:730-732

13. Tamachi Y, Hanzawa S, Momiki S, Sasaki K, Miyatani K: A case of traumatic hernia of diaphragm showing prolapse of liver with abnormal lobulation into pleural cavity. Nippon Kyobu Geka Gakkai Zasshi 1993, 41:2131-2135.

14. Keene $\mathrm{CH}$, Copleman $\mathrm{B}$ : Traumatic right diaphragmatic hernia: case with delayed herniation of the liver and gallbladder. Ann Surg 1945, 122:191-196.

15. Matsevych OY: Blunt diaphragmatic rupture: four year's experience. Hernia 2008, 12:73-78.

16. Christie DB 3rd, Chapman J, Wynne JL, Ashley DW: Delayed right-sided diaphragmatic rupture and chronic herniation of unusual abdominal contents. J Am Coll Surg 2007, 204:176.

17. Vaziri M: Late presentation of a right Bochdalek hernia with intrathoracic liver, gallbladder, intestines and omentum with right lower lobe hypoplasia. Ann Thorac Surg 2010, 90:1024.

18. Stefani A, Brandi L, Ruggiero C, Lodi R: A case of traumatic pericardiophrenic rupture. J Cardiovasc Surg 1998, 39:859-861.

19. Vilallonga R, Pastor V, Alvarez L, Charco R, Armengol M, Navarro S: Rightsided diaphragmatic rupture after blunt trauma. An unusual entity. World J Emerg Surg 2011, 18(6):3.

\section{Submit your next manuscript to BioMed Central and take full advantage of:}

- Convenient online submission

- Thorough peer review

- No space constraints or color figure charges

- Immediate publication on acceptance

- Inclusion in PubMed, CAS, Scopus and Google Scholar

- Research which is freely available for redistribution 